\title{
Study on the Efficacy and Safety of Policosanol in the Treatment of Senile and Elderly Patients with Hyperlipidemia
}

\author{
QING YE, L. F. HONG, K. PAN, XIN WANG AND X. M. YE*
}

Rehabilitation Medicine Center of Zhejiang Provincial People's Hospital, Rehabilitation \& Sports Medicine Research Institute of Zhejiang Province, People's Hospital of Hangzhou Medical College, Hangzhou 310014, China

Ye et al.: Efficacy and Safety of Policosanol in the Treatment of Hyperlipidemia

To investigate the efficacy, safety and tolerance of policosanol in the treatment of senile and elderly patients ( $\geq 75 \mathrm{y}$ old) with hyperlipidemia is the main objective. 150 senile and elderly patients with hyperlipidemia from June 2011 to May 2013 were randomly divided into two groups (test group and control group) according to the order of admission. The test group was treated with policosanol $10 \mathrm{mg} / \mathrm{d}$, while the control group was treated with atorvastatin $20 \mathrm{mg} / \mathrm{d}$ for $16 \mathrm{w}$. The changes and adverse reactions of total cholesterol, triglyceride, high density lipoprotein cholesterol, low density lipoprotein cholesterol, liver and kidney function, fasting blood glucose and creatine kinase were observed before and after treatment. There was no significant difference between the two groups in the indexes before treatment (p>0.05). After $16 \mathrm{w}$ treatment, total cholesterol, triglyceride, low density lipoprotein cholesterol and high density lipoprotein cholesterol in the test group were $5.51 \pm 0.77,1.79 \pm 0.88,3.68 \pm 0.65$ and $1.11 \pm 0.31 \mathrm{mmol} / \mathrm{l}$ before treatment and $4.90 \pm 1.03,1.26 \pm 0.64,3.21 \pm 0.92$ and $1.31 \pm 0.30 \mathrm{mmol} / \mathrm{l}$ after treatment, respectively. The above indexes had statistical significance before and after treatment $(\mathbf{p}<\mathbf{0 . 0 1})$. Total cholesterol, triglyceride, low density lipoprotein cholesterol and high density lipoprotein cholesterol in the control group were 5.59 \pm 1.10 , $1.90 \pm 0.76,3.68 \pm 1.00,1.18 \pm 0.37 \mathrm{mmol} / \mathrm{l}$ before treatment and $4.50 \pm 1.06,1.39 \pm 0.81,2.69 \pm 0.89,1.32 \pm 0.35$ $\mathrm{mmol} / \mathrm{l}$ after treatment, the above indexes were significantly different from those before treatment $(\mathrm{p}<0.01)$. In terms of the magnitude of lipid lowering, the policosanol group was weaker than the atorvastatin group, especially in lowering low density lipoprotein cholesterol $(p<0.01)$. No significant adverse reactions were observed in either group. Policosanol can effectively lower the level of blood lipid in patients and it is safe and well tolerated for senile and elderly patients.

Key words: Policosanol, atorvastatin, total cholesterol, triglyceride, low density lipoprotein cholesterol, high density lipoprotein cholesterol, hyperlipidemia

Dyslipidemia is a definite high risk factor for cardiovascular and cerebrovascular events. Several clinical studies have demonstrated that effective control of serum total cholesterol (TC) and/or low-density lipoprotein cholesterol (LDL-C) levels can significantly reduce the incidence and mortality of cardiovascular and cerebrovascular events ${ }^{[1,2]}$. Statins are currently the first-line lipid-lowering drugs in clinical practice, but statins can cause liver function and skeletal muscle damage in some patients and even induce the risk of death caused by skeletal muscle dissolution. In addition, statins have recently been found to have the risk of blood glucose abnormality and induced diabetes ${ }^{[3,4]}$.
The safety of statins is a serious challenge due to reduced organ compensation and repair in elderly patients and the potential for multiple co-morbidities. The newly published guidelines of the American College of Cardiology/American Heart Association (ACC/AHA) for the control of atherosclerotic cardiovascular risk in adults with reduced blood cholesterol no longer recommend the use of statins in elderly patients over $75 \mathrm{y}$ of age ${ }^{[5]}$. Therefore, it is necessary to search for other effective and safe drugs for patients with statin intolerance and senile and elderly patients. Policosanol is a new lipid-modifying drug, which can inhibit the synthesis of cholesterol and

*Address for correspondence

E-mail: yexmdr@126.com 
increase the blood clearance rate of LDL-C, effectively reduce the level of LDL-C and increase the level of high density lipoprotein cholesterol (HDL-C). Its clinical application has been confirmed by several clinical studies ${ }^{[6,7]}$. However, it has not been reported yet for the senile and elderly patients over 75 y old. Therefore, the aim of this study was to observe the efficacy and adverse reactions of policosanol and statins in the treatment of elderly patients over $75 \mathrm{y}$ old with hyperlipidemia and to provide a clinical basis for the rational selection of lipid-modifying drugs in senile and elderly patients. 150 patients aged $\geq 75$ y old with hyperlipidemia who were treated in our hospital from June 2011 to June 2013 were selected. 75 patients were randomly divided into the test group (policosanol group) and the control group (atorvastatin group) according to the order of treatment, including 39 males and 36 females, aged 78-93 y, with an average age of $83.66 \pm 3.31 \mathrm{y}$; the control group: 40 males and 35 females, aged 76-92 y, with an average age of $83.55 \pm 3.67 \mathrm{y}$. The diagnosis criteria of hyperlipidemia refer to "Guidelines for the Prevention and Treatment of Dyslipidemia in Chinese Adults" (2007 Edition ${ }^{[8]}$ ). Other inclusion criteria-The patients did not take other lipid-modifying drugs within $2 \mathrm{w}$ before enrollment and patients who took other lipid-modifying drugs should undergo a $2 \mathrm{w}$ drug washout period; all indexes of liver and kidney function tests were within normal range and the survival period was expected to be more than 6 mo. Exclusion criteria included-Inadequately controlled diet; patients with secondary dyslipidemia; patients with a history of cardiovascular and cerebrovascular events such as myocardial infarction or stroke within the past $6 \mathrm{mo}$; patients with chronic cardiac insufficiency; patients with hepatic and renal insufficiency; patients with a history of coagulopathy or a recent history of significant active bleeding and patients allergic to policosanol or statins. All the enrolled patients were randomly divided into the test group and the control group according to the sequence of treatment. The treatment regimen of the test group was policosanol (manufactured by Dalmar Laboratories Co., Ltd.) $10 \mathrm{mg} / \mathrm{d}$, while the treatment regimen of the control group was atorvastatin (manufactured by Pfizer Pharmaceutical China Co., Ltd., Trade name Lipitor) $20 \mathrm{mg} / \mathrm{d}$, all of which were taken within $1 \mathrm{~h}$ after daily dinner. Patients in both groups remained on their usual diet for the trial period of $16 \mathrm{w}$. Establish follow-up files to collect baseline data of all patients, mainly including: General condition of patients: age, height and body; laboratory test indexes: fasting blood glucose
(Glu), serum creatinine (Scr), blood urea nitrogen (BUN), aspartate aminotransferase (ALT), alanine aminotransferase (AST), creatine kinase (CK), TC, triglyceride (TG), LDL-C, HDL-C and high-sensitivity C-reactive protein (CRP). Baseline values and laboratory indexes at $16 \mathrm{w}$ were determined separately. The evaluation indexes include: Primary efficacy evaluation indexes: change of TC and LDL-C in the test group at w 16 compared with the baseline; secondary efficacy evaluation indexes: change of TG and HDL-C in the test group compared with the baseline at $\mathrm{w} 16$; safety indexes: mainly including ALT, AST, CK, Scr and BUN. Adverse reaction assessment: The patient has serious adverse reaction during treatment or has ALT or AST elevation more than 3 times of normal value or more or CK more than 10 times of normal value, even if not accompanied by any clinical manifestation, the test should be repeated within $1 \mathrm{w}$. If the patient has repeated test result of above persistent abnormal phenomenon, the patient should be withdrawn from the trial; if CK is more than 5-10 times of normal value and the patient is accompanied by myalgia, the administration should be stopped; in case of serious adverse reactions, the drug should be stopped immediately and corresponding symptomatic treatment should be given. Statistical package for the social sciences (SPSS) 20.0 software was used for statistical analysis. Values of various measurement parameters are expressed as mean \pm standard deviation $(\overline{\mathrm{x}} \pm \mathrm{s})$. Independent sample $t$ test is used for comparison between two groups. Paired data $t$ test is used for comparison before and after treatment. Adverse drug reactions are statistically described. The difference between the two groups was statistically significant $(p<0.05)$. Baseline data of the two groups before treatment was compared. A total of 150 patients were included in the two groups, 75 in the test group and 75 in the control group. Both groups had good medication compliance and none dropped out or withdrew from the group due to adverse drug reactions. The differences in baseline data before treatment between the two groups had no statistical significance $(p>0.05)$ and were comparable (Table 1). Changes of blood lipid levels before and after treatment in the two groups were compared. After $16 \mathrm{w}$ treatment, TC, TG and LDL-C levels in the test group and the control group were significantly decreased $(\mathrm{p}<0.01)$, while HDL-C levels were significantly increased. In the test group, TC decreased by $0.61 \mathrm{mmol} / 1$ and $11.07 \%$, LDL-C decreased by $0.47 \mathrm{mmol} / 1$ and $12.78 \%$, respectively. The mean TC of the control group decreased by 1.09 
$\mathrm{mmol} / \mathrm{l}, 19.48 \%$ drop compared with that before treatment and the mean LDL-C decreased by 0.99 $\mathrm{mmol} / 1,26.90 \%$ drop compared with that before treatment. These results suggested that the lipidlowering effect of policosanol, especially LDL-C lowering, in the test group was weaker than that of atorvastatin in the control group $(\mathrm{p}<0.01)$ (Table 2). Safety and adverse reactions of both groups were compared. In the control group, 2 patients had mild ALT elevation within 1.5 times of the upper limit of normal, no bilirubin elevation was observed and soon recovered to normal with hepatoprotective drugs; 5 patients had CK elevation within 2 times of the upper limit of normal and none had muscle pain symptoms. However, there was no significant difference in ALT, AST, CK, Scr and BUN between the two groups before and after treatment $(\mathrm{p}>0.05)$. In both groups, individual patients had the symptoms of drowsiness, dizziness, nausea and constipation, but the symptoms were mild and tolerable, without affecting the conduct of the trial. There were no serious adverse reactions in either group. Cardiovascular and cerebrovascular disease has become the first cause of death among the urban and rural population in China. Our cohort study suggests that elevated serum TC or LDL-C is an independent risk factor for coronary heart disease and ischemic stroke. A number of studies on TC reduction in CHD have also demonstrated a $1 \%$ reduction in serum TC and a $2 \%$ reduction in the risk of CHD events. An effective reduction in lipid levels would mean a significant reduction in the incidence of cardiovascular events and deaths from cardiovascular disease, as well as a reduction in overall mortality from cardiovascular disease. Therefore, the prevention and treatment of dyslipidemia has positive clinical significance. Statins significantly reduce serum LDL-C levels, resulting in significant reductions in mortality, cardiovascular events and disability in patients with coronary heart disease, establishing the important role of statins in lipid-lowering therapy. However, since statins have some damaging effects on liver and skeletal muscle and even induce the risk of death caused by skeletal muscle dissolution, recent studies have also shown that statins can cause abnormal blood glucose and induce the risk of diabetes mellitus. Therefore, safer and more effective lipid-lowering agents are needed in patients who cannot tolerate statins and in elderly patients with reduced visceral compensatory function. Policosanol is a newgeneration plant lipid-regulating drug derived from sugarcane wax of special sugarcane in western Cuba. The principal component of policosanol consists of 8 fatty alcohols of which 5 fatty alcohols contain more than 20 carbon atoms and are therefore termed policosanol. Unlike statins, policosanol acts primarily as a lipid-lowering agent via the following two pathways ${ }^{[9-12]}$ : Inhibits cholesterol synthesis by activating the Adenosine monophosphate (AMP)kinase pathway, inhibiting the activity of the key enzyme incholesterol synthesis, hydroxymethylglutarylCoA (HMG-CoA) reductase or increasing its degradation; increases blood clearance of LDL by increasing the number of low-density lipoprotein receptors and promotes the reduction of LDL-C in serum. In addition, experimental studies have shown that policosanol exerts antioxidant effects, inhibits platelet aggregation, inhibits smooth muscle cell proliferation and intimal hyperplasia, stabilizes plaques, improves vascular endothelial function and exerts antiatherosclerotic effects ${ }^{[13-15]}$. The clinical studies by Castano and Mas et al ${ }^{[6,16]}$ showed that $5 \sim 40 \mathrm{mg} / \mathrm{d}$ (average $12 \mathrm{mg} / \mathrm{d}$ ) policosanol could reduce LDL-C by about $23.7 \%$, TC by $10.5 \% \sim 24.2 \%$ and increase HDL-C by $9.0 \% \sim 31.4 \%$. High dose $(20 \mathrm{mg} / \mathrm{d})$ was also shown to reduce TG by $17.9 \%$. Fernandez et al:[7] showed good safety and tolerance of policosanol in elderly patients in a clinical observational study of more than 2200 elderly patients for up to $3 \mathrm{y}$. The purpose of this study was to investigate the efficacy, safety and tolerance of policosanol in the treatment of senile and elderly patients with hyperlipidemia in China by taking a special group of elderly patients over $75 \mathrm{y}$ old as the study objects and the effective atorvastatin as the control. The results showed that policosanol 10 $\mathrm{mg} / \mathrm{d}$ could reduce TC and LDL-C by more than $10 \%$ after $16 \mathrm{w}$ treatment, which suggested that it was effective in lipid-lowering. At the same time, the effects of lowering TG and increasing HDL-C were also observed. The lipid-lowering effect of policosanol 10 $\mathrm{mg} / \mathrm{d}$ was weaker than that of atorvastatin $20 \mathrm{mg} / \mathrm{d}$ compared with atorvastatin in the control group. The lipid-lowering effects of policosanol shown in this study are also slightly weaker than those reported in most of the literature ${ }^{[16-19]}$. Chen et al. ${ }^{[20]}$ conducted meta-analysis which showed that the maximum lipidlowering effect of policosanol occurred around $30 \mathrm{w}$ of treatment, whereas only the results at $16 \mathrm{w}$ were observed in this study. Meanwhile, the objects of this study were senile and elderly patients over $75 \mathrm{y}$ old. Most patients had multiple chronic diseases and took multiple drugs, which interfered with the pharmacokinetics and efficacy. In addition, considering that the subjects were senile and elderly patients, the 
dose was also small $(10 \mathrm{mg} / \mathrm{d})$. These reasons may have some impact on the outcome of the study. More clinical studies are needed to confirm whether there is a doseresponse relationship between the lipid-modifying effects of policosanol and the curves effect similar to that of statins. It has recently been reported in the domestic literature that policosanol plus low-dose atorvastatin $(10 \mathrm{mg} / \mathrm{d})$ may enhance lipid regulation with a guaranteed safety profile ${ }^{[21]}$. All the cases in this study had good medication compliance and none dropped out of the study or withdrew from the study due to adverse reactions. No hepatorenal function, muscle toxicity and other definite adverse reactions were observed in the policosanol group. The safety of policosanol in senile and elderly patients has been demonstrated. In conclusion, based on the results of this study and combined with most literatures at home and abroad, policosanol is safe and effective in the treatment of senile and elderly patients with hyperlipidemia, with few adverse reactions. However, the optimal dosage and treatment course of policosanol in the treatment of senile and elderly patients still need

TABLE 1: BASELINE DATA BEFORE TREATMENT IN THE TEST GROUP AND THE TREATMENT GROUP ( $\overline{\mathbf{X}} \pm \mathbf{s})$

\begin{tabular}{lcc}
\hline Group & Test group $(75$ cases) & Control group (75 cases) \\
\hline Age $(\mathrm{y}$ old $)$ & $83.66 \pm 3.31$ & $83.55 \pm 3.67$ \\
Gender ratio (male:female) & $39: 36$ & $40: 35$ \\
ALT $(\mathrm{U} / \mathrm{l})$ & $26.34 \pm 4.23$ & $25.68 \pm 6.57$ \\
AST $(\mathrm{U} / \mathrm{l})$ & $23.56 \pm 3.89$ & $22.47 \pm 4.55$ \\
Glu $(\mathrm{mmol} / \mathrm{l})$ & $5.36 \pm 1.24$ & $5.67 \pm 1.02$ \\
CK $(\mathrm{U} / \mathrm{l})$ & $78.43 \pm 28.33$ & $76.72 \pm 32.89$ \\
SCr $(\mu \mathrm{mol} / \mathrm{l})$ & $70.56 \pm 20.35$ & $75.46 \pm 25.48$ \\
BUN $(\mathrm{mmol} / \mathrm{l})$ & $5.43 \pm 1.24$ & $5.89 \pm 1.78$ \\
TC $(\mathrm{mmol} / \mathrm{l})$ & $5.51 \pm 0.77$ & $5.59 \pm 1.10$ \\
TG $(\mathrm{mmol} / \mathrm{l})$ & $1.79 \pm 0.88$ & $1.90 \pm 0.76$ \\
HDL-C $(\mathrm{mmol} / \mathrm{l})$ & $1.11 \pm 0.31$ & $1.18 \pm 0.37$ \\
LDL-C $(\mathrm{mmol} / \mathrm{l})$ & $3.68 \pm 0.65$ & $3.68 \pm 1.00$ \\
\hline
\end{tabular}

Note: $\mathrm{ALT}=$ aspartate aminotransferase; $\mathrm{AST}=$ alanine aminotransferase; $\mathrm{Glu}=$ fasting glucose; $\mathrm{CK}=\mathrm{creatine}$ kinase; $\mathrm{Scr}=\mathrm{serum} \mathrm{creatinine}$; $\mathrm{BUN}=$ blood urea nitrogen; $\mathrm{TC}=$ total cholesterol; TG=triglycerides; $\mathrm{HDL}-\mathrm{C}=$ high-density lipoprotein cholesterol; $\mathrm{LDL}-\mathrm{C}=$ low-density lipoprotein cholesterol; Independent sample t-test was used for comparison between groups, p>0.05

TABLE 2: COMPARISON OF MAIN EFFICACY INDEXES BEFORE AND AFTER TREATMENT BETWEEN THE TEST GROUP AND THE TREATMENT GROUP $(\overline{\mathbf{x}} \pm \mathbf{s})$

\begin{tabular}{lcccc}
\hline \multirow{2}{*}{ Efficacy indexes } & \multicolumn{2}{c}{ Policosanol group (test group) } & \multicolumn{2}{c}{ Atorvastatin group (control group) } \\
\cline { 2 - 5 } & Before treatment & After treatment & Before treatment & After treatment \\
\hline TC $(\mathrm{mmol} / \mathrm{l})$ & $5.51 \pm 0.77$ & $4.90 \pm 1.03$ & $5.59 \pm 1.10$ & $4.50 \pm 1.06^{\mathrm{a}}$ \\
TG $(\mathrm{mmol} / \mathrm{l})$ & $1.79 \pm 0.88$ & $1.26 \pm 0.64$ & $1.90 \pm 0.76$ & $1.39 \pm 0.81^{\mathrm{a}}$ \\
$\mathrm{HDL}-\mathrm{C}(\mathrm{mmol} / \mathrm{l})$ & $1.11 \pm 0.31$ & $1.31 \pm 0.30$ & $1.18 \pm 0.37$ & $1.32 \pm 0.35^{\mathrm{a}}$ \\
LDL-C $(\mathrm{mmol} / \mathrm{l})$ & $3.68 \pm 0.65$ & $3.21 \pm 0.92$ & $3.68 \pm 1.00$ & $2.69 \pm 0.89^{\mathrm{a}, \mathrm{b}}$ \\
\hline
\end{tabular}

Note: TC=total cholesterol; TG=triglyceride; HDL-C=high density lipoprotein cholesterol; $\mathrm{LDL}-\mathrm{C}=$ =low density lipoprotein cholesterol; aPaired $t$ test was used for comparison before and after treatment, $p<0.01$; Independent sample $t$ test was used for comparison between groups after treatment, $\mathrm{p}<0.01$ 
further clinical study.

\section{Conflicts of interest:}

The authors declared no conflict of interest.

\section{REFERENCES}

1. Taylor F, Ward K, Moore TH, Burke M, Smith GD, Casas JP, et al. Statins for the primary prevention of cardiovascular disease. Cochrane Database Syst Rev 2013(1):CD004816.

2. Brugts JJ, Yetgin T, Hoeks SE, Gotto AM, Shepherd J, Westendorp RG, et al. The benefits of statins in people without established cardiovascular disease but with cardiovascular risk factors: meta-analysis of randomised controlled trials. BMJ 2009;338:b2376.

3. Preiss D, Seshasai SR, Welsh P, Murphy SA, Ho JE, Waters $\mathrm{DD}$, et al. Risk of incident diabetes with intensive-dose compared with moderate-dose statin therapy: A meta-analysis. JAMA 2011;305(24):2556-64.

4. Sattar N, Preiss D, Murray HM, Welsh P, Buckley BM, de Craen AJ, et al. Statins and risk of incident diabetes: A collaborative meta-analysis of randomised statin trials. Lancet 2010;375:735-42.

5. Stone NJ, Robinson JG, Lichtenstein AH, Bairey Merz CN, Blum CB, Eckel RH, et al. 2013 ACC/AHA guideline on the treatment of blood cholesterol to reduce atherosclerotic cardiovascular risk in adults: a report of the American College of Cardiology/American Heart Association Task Force on Practice Guidelines. J Am Coll Cardiol 2014;63:2889-934.

6. Castano G, Mas R, Fernandez L, Illnait J, Mendoza S, Gamez $\mathrm{R}$, et al. A comparison of the effects of D-003 and policosanol (5 and $10 \mathrm{mg} /$ day) in patients with type II hypercholesterolemia: a randomized, double-blinded study. Drugs Exp Clin Res 2005;31:31-44.

7. Fernandez S, Rosa M, Gamez R, Diaz A, Fernandez J, Illnait J, et al. A pharmacological surveillance study of the tolerability of policosanol in the elderly population. Am J Geriatr Pharmacother 2004;2(4):219-29.

8. Chinese Joint Committee on the Development of Guidelines for the Prevention and Treatment of Dyslipidemia in Adults. Chinese Guidelines for the Prevention and Treatment of Dyslipidemia in Adults. Chin J Cardiovasc Dis 2007;35(5):390419.

9. Banerjee S, Ghoshal S, Porter TD. Activation of AMP-kinase by policosanol requires peroxisomal metabolism. Lipids 2011;46(4):311-21.

10. Oliaro-Bosso S, Calcio Gaudino E, Mantegna S, Giraudo E, Meda C, Viola F, et al. Regulation of HMGCoA reductase activity by policosanol and octacosadienol, a new synthetic analogue of octacosanol. Lipids 2009;44(10):907-16.

11. McCarty MF. Policosanol safely down-regulates HMG-CoA reductase-potential as a component of the Esselstyn regimen. Med Hypotheses 2002;59(3):268-79.
12. Singh DK, Li L, Porter TD. Policosanol inhibits cholesterol synthesis in hepatoma cells by activation of AMP-kinase. J Pharmacol Exp Ther 2006;318(3):1020-6.

13. Noa M, Mas R. Protective effect of policosanol on atherosclerotic plaque on aortas in monkeys. Arch Med Res 2005;36(5):441-7.

14. Castano G, Fernandez L, Mas R, Illnait J, Mesa M, Fernandez JC. Comparison of the effects of policosanol and atorvastatin on lipid profile and platelet aggregation in patients with dyslipidaemia and type 2 diabetes mellitus. Clin Drug Investig 2003;23(10):639-50.

15. Arruzazabala ML, Molina V, Mas R, Fernandez L, Carbajal D, Valdes S, et al. Antiplatelet effects of policosanol (20 and 40 $\mathrm{mg}$ /day) in healthy volunteers and dyslipidaemic patients. Clin Exp Pharmacol Physiol 2002;29(10):891-7.

16. Castano G, Mas R, Fernandez L, Illnait J, Mesa M, Alvarez $\mathrm{E}$, et al. Comparison of the efficacy and tolerability of policosanol with atorvastatin in elderly patients with type II hypercholesterolaemia. Drugs Aging 2003;20(2):153-63.

17. Shen L, Cui J. Cost-effectiveness analysis of policosanol and rosuvastatin in treatment of senior patients with hyperlipidemia. Clin Misdiagn Misther 2011;10:87-9.

18. Wang Y, Ke YN, Wang JL, Jiao Y, Zhao XL, Sun NL, et al. Efficacy and safety of policosanol and pravastatin in treatment of hyperlipidemia in Chinese patients. Chin J New Drugs Clin Rem 2008;27(2):124-8.

19. Castano G, Mas R, Fernandez L, Gamez R, Illnait J. Effects of policosanol and lovastatin in patients with intermittent claudication: A double-blind comparative pilot study. Angiology 2003;54(1):25-38.

20. Chen JT, Wesley R, Shamburek RD, Pucino F, Csako G. Meta-analysis of natural therapies for hyperlipidemia: Plant sterols and stanols versus policosanol. Pharmacotherapy 2005;25(2):171-83.

21. Jianjiang Z, Jun Y, Jingbo Y, Zuo L, Ying C, Hongxia W. Clinical observation on efficacy and safety of policosanol combined with low-dose atorvastatin in the treatment of elderly patients with diabetes mellitus complicated with hyperlipidemia. Zhejiang Med J 2013;(20):1827-9.

This is an open access article distributed under the terms of the Creative Commons Attribution-NonCommercial-ShareAlike 3.0 License, which allows others to remix, tweak, and build upon the work non-commercially, as long as the author is credited and the new creations are licensed under the identical terms

This article was originally published in a special issue,

"Therapeutic Perspectives in Biomedical Research and Pharmaceutical Sciences and their Nursing Methods"

Indian J Pharm Sci 2021:83(4)Spl issue "77-81" 